\title{
Pharmacovigilance Programme of India: System put in place to Report Adverse Drug Reactions
}

\author{
Vivekanandan Kalaiselvan ${ }^{1}$, Ismeet Kaur ${ }^{1 *}$, Surinder Singh ${ }^{2}$ and Gyanendra N Singh ${ }^{1}$ \\ ${ }^{1}$ Indian Pharmacopoeia Commission, Ministry of Health \& Family Welfare, Govt of India, Sector 23, Rajnagar, Ghaziabad, U.P.-201002, India. \\ ${ }^{2}$ National Institute of Biologics (NIB), Ministry of Health \& Family Welfare, Govt. of India, Plot No. A-32, Sector-62, Institutional Area, \\ NOIDA, U.P.-201 309, India.
}

\section{Dear Editor,}

Adverse drug reaction (ADRs) is response to a drug which is noxious and unintended and which occurs at doses normally used in human for the prophylaxis, diagnosis or treatment of disease, or for the modification of physiological function. ${ }^{1}$ ADRs are one of the major public health issues and found to cause of morbidity and mortality. ${ }^{2}$ The impact of ADRs in India is significant and leads to the enormous burden to the public. Therefore, Ministry of Health \& Family Welfare (MoHFW), Government of India launched a nationwide Pharmacovigilance Programme of India (PvPI) in the year 2010 to monitor the safety of drugs. Indian Pharmacopoeia Commission (IPC) under the MoHFW functions as National Coordination Centre (NCC) for PvPI. To monitor and report ADRs to NCC, teaching hospitals and corporate hospitals have been identified as ADRs Monitoring Centres (AMCs)..$^{3-5} \mathrm{ADR}$ reporters (healthcare professionals) who is not a part of AMC can also fill the suspected ADR reporting form (Figure 1) and submit to nearby AMC (available at www.ipc.gov.in). Reporter can call on 'PvPI-Helpline-1800 180 3024' for further assistance in ADRs reporting. ${ }^{6}$ To report ADRs simply and quickly, NCC introduced android mobile application which will also enhance the participation of private practitioners. All types of suspected adverse events with all pharmaceutical products irrespective of whether they are known or unknown, serious or non-serious and frequent or rare can be reported. The obtained information is entered in the drug safety database Vigiflow ${ }^{\mathrm{TM}}$ (webbased software for International Drug Monitoring in the WHO Programme), analysed and assessed by the experts to identify new signals. This is also used as a main source for identifying and reducing the risks associated with the drugs. Submission of ADRs report does not have any legal implication on the reporter and also the confidentiality of the reporter and patients will be maintained. The provided information contributes to promote patients' safety in many ways such as generation of drug safety data on Indian population, for taking appropriate regulatory decisions, educational initiatives for healthcare professionals for promoting safety of medicines, benefit-risk assessment, updating prescribing information leaflet (ADRs, warning, contraindication etc) and promote rational use of medicines. Therefore, healthcare providers are encouraged to report ADRs for better understanding and to safeguard the health of Indian population.
Submission Date :03-12-2014

Revised Date : :22-06-2015 Accepted Date : :19-07-2015

DOI: 10.5530/ijper.50.1.26 Correspondence Address Ismeet Kaur, M. Pharm Technical Associate, Indian Pharmacopoeia Commission, Sector 23, Rajnagar, Ghaziabad, UP-201002, India. Phone:08130581910 Email:ishunarang12@gmail. com

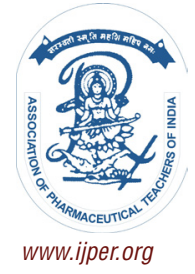


Version-1.2

\section{SUSPECTED ADVERSE DRUG REACTION REPORTING FORM}

For VOLUNTARY reporting of Adverse Drug Reactions by Healthcare Professionals

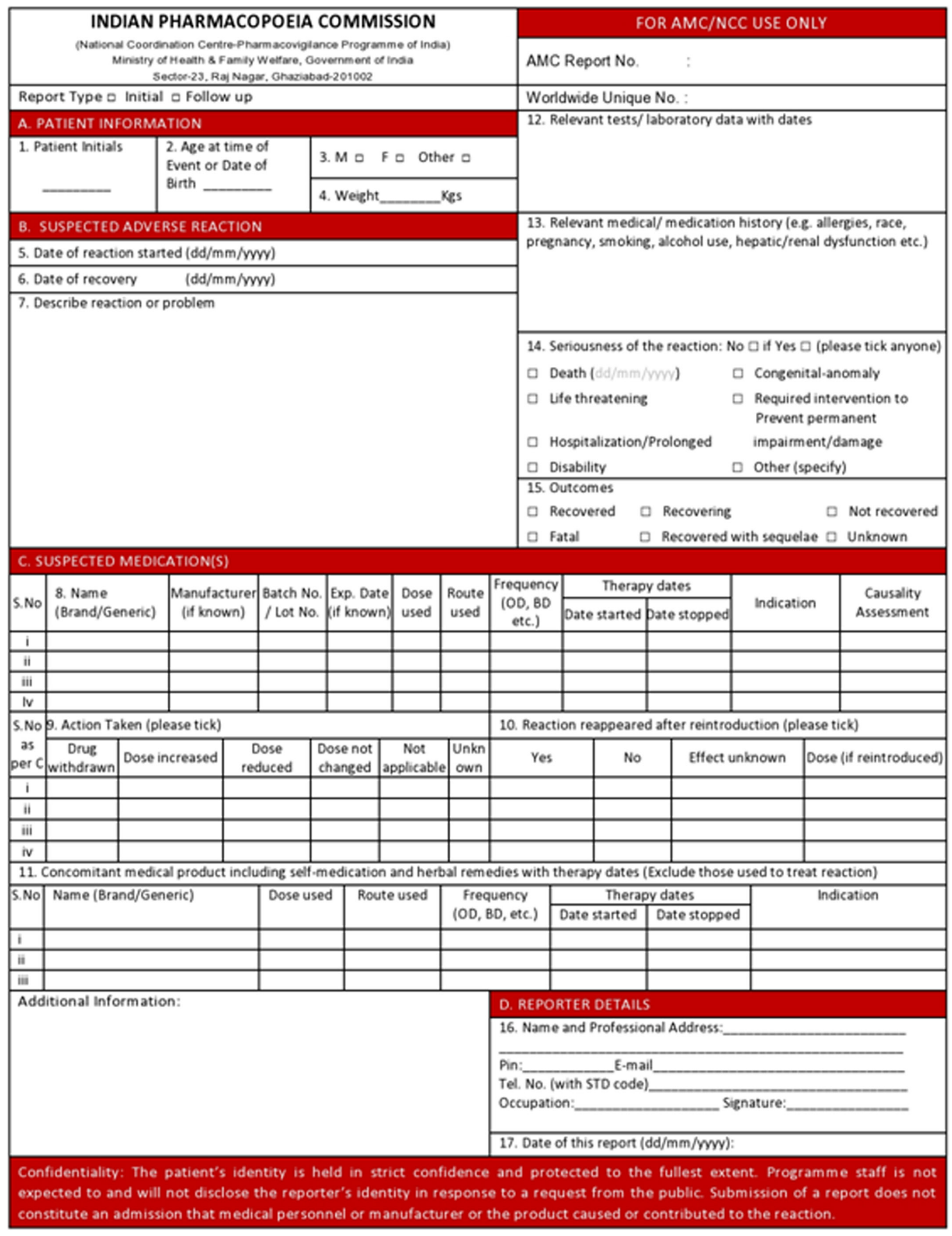



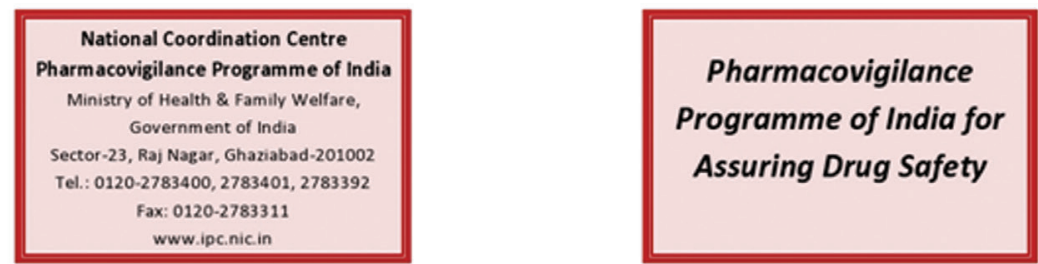

\section{ADVICE ABOUT REPORTING}

\section{A. What to report}

- Report serious adverse drug reactions. A reaction is serious when the patient outcome is:

- Death

- Life-threatening

- Hospitalization (initial or prolonged)

- Disability (significant, persistent or permanent)

- Congenital anomaly

- Required intervention to prevent permanent impairment or damage

- Report non-serious, known or unknown, frequent or rare adverse drug reactions due to Medicines, Vaccines and Herbal products.

\section{B. Who can report}

- All healthcare professionals (Clinicians, Dentists, Pharmacists and Nurses) can report adverse drug reactions C. Where to report

- Duly filled Suspected Adverse Drug Reaction Reporting form can be send to the nearest Adverse Drug Reaction Monitoring Centre (AMC) or directly to the National Coordination Centre (NCC).

- Call on Helpline (Toll Free) 18001803024 to report ADRs.

> Or can directly mail this filled form to pvpi@ipcindia.net or pvpi.ipcindia@gmail.com

- A list of nationwide AMCs is available at:

http://www.ipc.gov.in, http://www.ipc.gov.in/PvPI/pv_home.htm/

D. What happens to the submitted information

- Information provided in this form is handled in strict confidence. The causality assessment is carried out at AMCs by using WHO-UMC scale. The analyzed forms are forwarded to the NCC through ADR database. Finally the data is analyzed and forwarded to the Global Pharmacovigilance Database managed by WHO Uppsala Monitoring Centre in Sweden.

- The reports are periodically reviewed by the NCC-PvPI. The information generated on the basis of these reports helps in continuous assessment of the benefit-risk ratio of medicines.

- The information is submitted to the Steering committee of PvPI constituted by the Ministry of Health \& Family Welfare. The Committee is entrusted with the responsibility to review the data and suggest any interventions that may be required.

E. Mandatory field for suspected ADR reporting form

- Patient initials, age at onset of reaction, reaction term(s), date of onset of reaction, suspected medication(s) and reporter information.

For ADRs Reporting Call on PVPI Helpline (Toll Free)

18001803024

(9:00 AM to 5:30 PM, Working Days)

\section{REFERENCES}

1. World Health Organization. International Drug Monitoring: The Role of National Centres, Technical Report Series No. 498. Geneva: World Health Organization; 1972.

2. Tai YW, Min HJ, Alex B, Mariam M, Paul A, Derek B, Azeem M. Ten-year trends in hospital admissions for adverse drug reactions in England 1999-2009. J R Soc Med 2010; 103: 230-250.

3. V. Kalaiselvan, Surbhi S, G.N Singh. Adverse reactions to contrast media: An analysis of spontaneous reports in the database of the Pharmacovigilance Programme of India. Drug Safety 2014; 37: 703-10.
4. Vishal RT, Vijay K, Annil M, Zahid G, Vlvek M, Vijant C. Fatal adverse drug reactions: Experience of adverse drug reactions in a tertiary care teaching hospital of North India-A case series. Ind J Critical Care Medicine 2014; 18(5): 315-9.

5. Sriram S, Ghasemi A, Rajeswari R, Manjula D, Rajalingam B, Ravi TK, et al. Prevalence of adverse drug reactions at a private tertiary care hospital in south India. J Res Med Sci. 2011; 16(1): 16-25.

6. V. Kalaiselvan, P. Mishra, G. N. Singh. Helpline facility to assist reporting of adverse drug reactions in India. WHO South-East Asia Journal of Public Health 2014; 3: 194. 